\title{
How to Assess the Effectiveness of Energy Management Processes in Water Supply Systems
}

\author{
Nelson CARRIÇO*, Dídia COVAS*, Helena ALEGRE**, Maria ALMEIDA** \\ * Instituto Superior Técnico, Technical University of Lisbon, Portugal, \\ nelson.carrico@ist.utl.pt, didia.covas@ist.utl.pt \\ **Urban Water Division, Hydraulics and Environment Department, LNEC - National \\ Laboratory of Civil Engineering, Portugal, halegre@Inec.pt, mcalmeida@lnec.pt
}

Abstract: The current paper presents criteria and performance measures for the assessment of the effectiveness of energy management processes in water supply systems. The main objectives that motivate the implementation of energy management strategies are identified, assessment criteria for each objective and the corresponding performance indicators to be used are recommended. Novel performance indices for evaluating energy efficiency are presented and applied to a real-life water supply system for different consumption scenarios and operating schemes. Results obtained are discussed.

Key words: energy efficiency; energy management; water supply; performance indicators.

(C) Asset management for enhancing energy efficiency in water and wastewater systems, International Water Association, Marbella - Spain, 24-26 April 2013. 